\title{
Analisa Studi Keandalan Sistem Distribusi 20 KV di PT. PLN (PERSERO) UPJ Mojokerto Menggunakan Metode FMEA (FAILURE MODE EFFECT ANALYSIS)
}

\author{
Aang Fras Setiawan ${ }^{1}$, Titiek Suheta ${ }^{2}$ \\ Jurusan Teknik Elektro Institut Teknologi Adhi Tama Surabaya \\ Jl. Arief Rachman Hakim no.100 Surabaya \\ email : aang.fras.s14@gmail.com \\ hita@itats.ac.id
}

\begin{abstract}
ABSTRAK - Keandalan sistem distribusi merupakan kemampuan sistem untuk memberikan suatu pasokan tenaga listrik yang cukup dengan kualitas memuaskan. Peningkatan kebutuhan tenaga listrik, menuntut tingkat keandalan yang lebih tinggi dalam penyediaan dan penyaluran dayanya. Tujuan penelitian ini adalah untuk menghitung tingkat keandalan sistem distribusi $20 \mathrm{kV}$ pada UPJ Mojokerto dengan metode Failure Mode Effect Analysis (FMEA), di mana nilai dari indeks kegagalan dari setiap peralatan utama sistem distribusi diperhitungkan untuk mencari nilai indeks keandalan sistem secara menyeluruh. Studi kasus dilakukan di PT. PLN (persero) UPJ Mojokerto guna melihat pengaruh dari jumlah serta lokasi penempatan sectionalizer di sepanjang jaringan terhadap indeks keandalan sistem. Hasil analisa pada penyulang Gading didapatkan nilai SAIFI berdasarkan metode FMEA adalah 3,80237 dan simulasi sebesar 3,8174 sedangkan untuk nilai SAIDI adalah 11,9697 dan 12,1197. Dan untuk penyulang Bangsal nilai SAIFI berdasarkan metode FMEA sebesar 6,82974 dan simulasi sebesar 6,4743 sedangkan nilai SAIDI adalah 13,9370443 dan 14,5671. Nilai SAIFI dan SAIDI pada penyulang Gading dan Bangsal belum mencapai nilai standart yang di tetapkan oleh PT. PLN (persero), maka perlu di tingkatkan guna mencapai keandalan sistem distribusi yang baik.
\end{abstract}

Kata Kunci : Keandalan, Sistem Distribusi, SAIDI, SAIFI, FMEA

ABSTRACT - Reliability of a distribution system is the ability of the system to provide a sufficient supply of electric power with satisfactory quality. Increased demand for electricity, demands a higher level of reliability in the supply and distribution of power. The purpose of this study was to calculate the reliability level of the $20 \mathrm{kV}$ distribution system at UPJ Mojokerto using the Failure Mode Effect Analysis (FMEA) method, where the value of the failure index of each major equipment distribution system was calculated to find the overall system reliability index value. Case studies conducted at PT. PLN (Persero) UPJ Mojokerto to see the effect of the number and location of the placement of sectionalizers along the network against the system reliability index. The results of analysis on Ivory feeders obtained SAIFI values based on the FMEA method were 3.80237 and the simulation was 3.8174 while those for SAIDI values were 11.9697 and 12.1197. And for Bangsal feeders, the SAIFI value based on the FMEA method is 6.82974 and the simulation is 6.4743 while the SAIDI values are 13.9370443 and 14.5671 . The value of SAIFI and SAIDI for Ivory feeders and Bangsal has not yet reached the standard value set by PT. PLN (Persero), it needs to be improved in order to achieve good distribution system reliability.

Keywords: Reliability, Distribution System, SAIDI, SAIFI, FM

\section{PENDAHULUAN}

Unit Pelayanan Jaringan (UPJ) Rayon Mojokerto merupakan jaringan atau mempunyai wilayah kerja di Unit PT. PLN (Persero), bertugas untuk penerimaan hasil penjualan tenaga listrik, peningkatan kualitas pelayanan, pelaksanaan pengelolaan Jaringan Tegangan Menengah (JTM), Jaringan Tegangan Rendah (JTR), Sambungan Rendah (SR),Alat Pembatas dan Pengukur (APP), pengelolaan keuangan serta pengelolaan SDM dan administrasi, membina hubungan kerja, kemitraan dan komunikasi yang efektif guna menjaga citra perusahaan serta mewujudkan Good Coorporate Governance. Rayon Mojokerto merupakan daerah yang berpotensi mempunyai kawasan industri yang besar,namun pada penyulang tertentu sering terjadi gangguan yaitu pada penyulang Gading dan Bangsal. Sehingga perlunya ditingkatkan nilai keandalannya dengan cara mengurangi frekuensi terjadinya gangguan dan dilakukan pemeliharaan jaringan secara preventif.

Metode yang digunakan untuk meningkatkan nilai keandalan adalah Failure Mode Effect Analysis (FMEA),yaitu dengan cara memecah sistem dalam bagian-bagian yang lebih kecil atau section terlebih dahulu,sehingga kemungkinan terjadinya kesalahan dapat diminimalkan dan waktu yang dibutuhkan lebih singkat [2]. 


\section{STUDI PUSTAKA}

Keandalan Sistem Distribusi 20 kV PT.PLN Rayon Lumajang menggunakan Metode FMEA (Failure Modes and Effects Analysis), dalam penelitian ini menghitung indeks keandalan dari sistem distribusi $20 \mathrm{kV}$ Rayon Lumajang. Berdasarkan hasil analisa saat penambahan fuse pada penyulang Sukodono akan dapat menaikkan Indeks Keandalan SAIFI yang semula bernilai 6.6088 menjadi 5.4176, dan dengan penambahan sectionalizer dapat menaikkan indeks keandalan SAIDI yang awalnya bernilai 7.6737 menjadi $6.4431 .[5]$

Keandalan dapat didefinisikan sebagai probabilitas bahwa perangkat atau sistem akan melakukan tugas yang diberikan di bawah kondisi lingkungan tertentu untuk jangka waktu tertentu, sementara ketersediaan adalah bahwa sistem akan dapat melakukan sebagaimana fungsinya yang diperlukan selama periode waktu tertentu.[6]

\section{METODE}

Penelitian dilakukan di PT. PLN UPJ Rayon Mojokerto yang bertempat di JL. Jend. Ahmad Yani No. 6, Mojokerto, Jawa Timur 61331.

Tahapan-tahapan yang dilakukan dalam penelitian ini :

1. Pengambilan data trafo,penyulang dan panjang saluran.

2. Menghitung beban pada kegagalan trafo, switch dan kabel berdasarkan data standart nilai laju kegagalan.

Tabel 1. Standart Nilai Laju Kegagalan

\begin{tabular}{|c|l|l|c|}
\hline $\begin{array}{c}\mathrm{N} \\
\mathrm{o}\end{array}$ & \multicolumn{1}{|c|}{ Komponen } & \multicolumn{1}{|c|}{ Lamda } & $\begin{array}{c}\text { Repair Time } \\
\text { (jam) }\end{array}$ \\
\hline 1 & Saluran udara & $0.2 / \mathrm{km} / \mathrm{tahun}$ & 4 \\
\hline 2 & Pemutus tenaga & $0.004 /$ unit/tahun & 10 \\
\hline 3 & Saklar pemisah & $0.003 /$ unit/tahun & 10 \\
\hline 4 & Trafo distribusi & $0.005 /$ unit/tahun & 10 \\
\hline 5 & Saklar beban & $0,003 /$ unit/tahun & 10 \\
\hline
\end{tabular}

3. Dengan metode FMEA untuk

- menetukan nilai keandalan SAIF

$=\frac{\text { Jumlah dari perkalian frekuensi padam } x \text { jumlah pelanggan }}{\text { jumlah seluruh pelanggan }}$

- menentukan nilai keandalan SAIDI

$=\frac{\text { Jumlah dari perkalian waktu/durasi padam } x \text { jumlah pelanggan }}{\text { jumlah seluruh pelanggan }}(2)$

- menentukan nilai keandalan CAIDI

$=\frac{\text { Jumlah durasi gangguan pelanggan }}{\text { jumlah gangguan pelanggan }}$

- menentukan nilai keandalan ASAI $=\frac{\text { Jumlah pelanggan layanan yang tersedia }}{\text { jam pelanggan diminta }}$
- menentukan nilai keandalan ASUI

$=\frac{\text { Jumlah pelanggan layanan yang tidak tersedia }}{\text { jampelanggan diminta }}$

IV. HASIL DAN PEMBAHASAN

Tabel 2. Load Point yang Dipengaruhi Standart Nilai Laju Kegagalan.

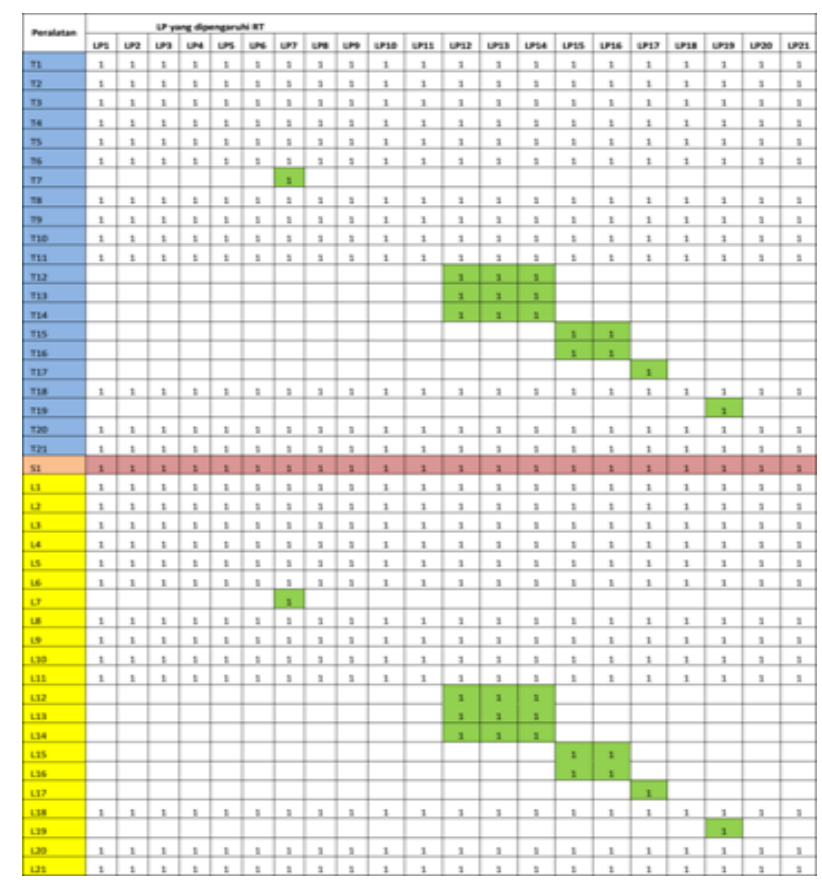

1. Hasil perhitungan pada load 1 yang di pengaruhi switch

Apabila terjadi kegagalan pada switch 1,maka kegagalan yang mempengaruhi load 1 dari switch adalah switch 1 sehingga di peroleh :

Indeks kegagalan switch $=0,003 \times 1$ ( switch yang mempengaruhi kegagalan pada load 1$)=0,003 \lambda$.

2. Hasil perhitungan pada load 1 yang di pengaruhi kabel. Apabila terjadi kegagalan pada kabel 1,maka kegagalan yang mempengaruhi load 1 dari kabel adalah kabel $1 \mathrm{~s} / \mathrm{d}$ kabel 6, kabel $8 \mathrm{~s} / \mathrm{d}$ kabel 11, kabel 18, kabel 20 dan kabel 21 sehingga di peroleh :

Indeks kegagalan kabel $=0,2 \times 16,965$ panjang masing-masing kabel (kabel yang mempengaruhi kegagalan pada load 1$)=3,393$

Maka total lamda dari load $1=0,065+0,003+$ $3,393+0,004(\mathrm{cb})=3,465 \lambda$.

Perhitungan kegagalan pada data panjang kabel yang dipengaruhi repair time ditunjukkan pada Tabel 3. 
Point (lampiran 1).

Tabel 3. Data Panjang Kabel yang Dipengaruhi kegagalan

\begin{tabular}{|c|c|c|}
\hline \multicolumn{3}{|c|}{ Data Panjang Kabel } \\
\hline Saluran & $\mathrm{L}(\mathrm{Km})$ & $\begin{array}{c}\text { Kabel yang } \\
\text { dipengaruhi kegagalan }\end{array}$ \\
\hline L1 & 12.296 & 12.296 \\
\hline L2 & 0.596 & 0.596 \\
\hline L3 & 0.528 & 0.528 \\
\hline $\mathrm{L} 4$ & 1.001 & 1.001 \\
\hline L5 & 0.096 & 0.096 \\
\hline L6 & 0.059 & 0.059 \\
\hline L7 & 0.226 & \\
\hline L8 & 0.514 & 0.514 \\
\hline L9 & 0.439 & 0.439 \\
\hline L10 & 0.103 & 0.103 \\
\hline L11 & 0.122 & 0.122 \\
\hline L12 & 0.139 & \\
\hline L13 & 0.676 & \\
\hline L14 & 1.413 & \\
\hline L15 & 1.884 & \\
\hline L16 & 1.455 & \\
\hline L17 & 1.051 & \\
\hline L18 & 0.458 & 0.458 \\
\hline L19 & 0.247 & \\
\hline L20 & 0.439 & 0.439 \\
\hline L21 & 0.314 & 0.314 \\
\hline $\begin{array}{l}\text { Nilai } \\
\text { Keseluruhan }\end{array}$ & 24.056 & \\
\hline \multicolumn{2}{|c|}{$\begin{array}{l}\text { Nilai yang dipengaruhi } \\
\text { kegagalan }\end{array}$} & 16.965 \\
\hline
\end{tabular}

1. Hasil Perhitungan U (waktu/durasi kegagalan) Indeks dari laju kegagalan masing-masing dikalikan dengan repair time, didapatkan :

$0,065 \times 10=0,65$

$0,003 \times 10=0,03$

$3,393 \times 3=10,179$

$0,004 \times 10=0,04$

Sehingga total $\mathrm{U}$ (waktu/durasi kegagalan) dari

load 1 adalah $=0,65+0,03+10,179+0,04(\mathrm{cb})$

$=10,899 \mathrm{U}$.

2. Hasil perhitungan $S A I F I$ :

3. Hasil perhitungan SAIDI :

$$
S A I F I=\frac{3.465 \times 416}{3257}=0,44257
$$

$$
S A I D I=\frac{10.899 \times 416}{3257}=1,39207
$$

4. Hasil perhitungan CAIDI :

$$
C A I D I=\frac{1,39207}{0,44257}=3,14545
$$

5. Hasil perhitungan ASAI :

$$
\begin{aligned}
& A S A I=\frac{(416 \times 8760)-(416 \times 10899)}{416 \times 8760} \\
& =\frac{3664160-4533,984}{3664160}=0,99876
\end{aligned}
$$

6. Hasil perhitungan ASUI :

$$
\begin{gathered}
A S U I=\frac{(416 \times 10899)}{416 \times 8760}=\frac{4533,984}{3664160} \\
=0.00124
\end{gathered}
$$

7. Hasil perhitungan indeks keandalan dengan Metode FMEA pada Penyulang Gading per-Load
Tabel 4. Hasil Evaluasi Indeks Keandalan Penyulang Gading

\begin{tabular}{|l|l|}
\hline \multicolumn{2}{|c|}{ FMEA } \\
\hline SAIFI & 3.80237 \\
\hline SAIDI & 11.9697 \\
\hline CAIDI & 3.14796 \\
\hline ASAI & 0.9987 \\
\hline ASUI & 0.0013 \\
\hline
\end{tabular}

Tabel 5. Hasil Evaluasi Indeks Keandalan dengan simulasi pada penyulang Gading

\begin{tabular}{|c|c|}
\hline \multicolumn{2}{|c|}{ Simulasi } \\
\hline SAIFI & 3.8174 \\
\hline SAIDI & 12.1197 \\
\hline CAIDI & 3.175 \\
\hline ASAI & 0.9986 \\
\hline ASUI & 0.00138 \\
\hline
\end{tabular}

8. Hasil perhitungan indeks keandalan dengan metode FMEA pada penyulang Bangsal perLoad Point (lampiran 2).

Tabel 6. Hasil Evaluasi Indeks Keandalan Penyulang Bangsal

\begin{tabular}{|l|l|}
\hline \multicolumn{2}{|c|}{ FMEA } \\
\hline SAIFI & 6.82974 \\
\hline SAIDI & 13.9370443 \\
\hline CAIDI & 2.04064 \\
\hline ASAI & 0.99862 \\
\hline ASUI & 0.001378 \\
\hline
\end{tabular}

Tabel 7. Hasil Evaluasi Indeks Keandalan dengan simulasi pada penyulang Bangsal

\begin{tabular}{|c|c|}
\hline \multicolumn{2}{|c|}{ Simulasi } \\
\hline SAIFI & 6.4743 \\
\hline SAIDI & 14.5671 \\
\hline CAIDI & 2.250 \\
\hline ASAI & 0.9983 \\
\hline ASUI & 0.00166 \\
\hline
\end{tabular}

9. Rekapitulasi Semua Penyulang

Tabel 7. Data Topologi Penyulang

\begin{tabular}{|c|c|c|c|c|c|c|}
\hline $\begin{array}{c}\text { Penyul- } \\
\text { ang }\end{array}$ & $\begin{array}{c}\text { Panjang } \\
\text { SUTM } \\
(\mathrm{Km})\end{array}$ & $\begin{array}{c}\text { Load } \\
\text { Point }\end{array}$ & $\begin{array}{c}\text { Jumlah } \\
\text { pelanggan }\end{array}$ & $\begin{array}{c}\text { Jumla } \\
\mathrm{h} \\
\text { switch }\end{array}$ & $\begin{array}{c}\text { Jumla } \\
\mathrm{h} \\
\text { fuse }\end{array}$ & $\begin{array}{c}\text { Jumla } \\
\mathrm{h} \\
\text { kabel }\end{array}$ \\
\hline Gading & 24.056 & 21 & 3257 & 1 & 5 & 21 \\
\hline Bangsal & 46.862 & 61 & 11729 & 5 & 8 & 61 \\
\hline
\end{tabular}

Semakin panjang suatu saluran maka nilai SAIDI dan SAIFI juga semakin rendah,dan untuk mengkompensasi nilai laju kegagalan maka dibutuhkan fuse yang banyak. Karena fuse dapat difungsikan untuk menurunkan nilai lamda per-load point. Dan juga dibutuhkan switch yang banyak pula untuk mengkompensasi adanya durasi saat repair time berlangsung. 


\section{KESIMPULAN}

Berdasarkan hasil analisa dan simulasi dapat diambil beberapa kesimpulan :

1. Pada penyulang Gading dengan metode FMEA dan simulasi terdapat selisih nilai SAIFI sebesar 0,01503 dan SAIDI $=0,15$, hal ini menunjukkan pada penyulang Gading nilai SAIFI dan SAIDI masih belum mencapai nilai standart yang di tetapkan oleh PT. PLN (persero).

2. Pada penyulang Bangsal dengan metode FMEA dan simulasi terdapat selisih nilai SAIFI sebesar 0,35544 dan SAIDI $=0,63005$ hal ini menunjukkan pada penyulang Bangsal nilai SAIFI dan SAIDI masih belum mencapai nilai standart yang di tetapkan oleh PT. PLN (persero).

\section{REFERENSI}

1. Afandi, A. 2017. Studi Keandalan Sistem Distribusi 20kV di PT. PLN (PERSERO) UPJ Jombang Menggunakan Metode Failure Mode Effect Analysis (FMEA). Jurnal : Jurusan Teknik Elektro, Fakultas Teknik. Surabaya: Universitas Negeri Surabaya.

2. Akbari, Mohsen, P. Khazaee. 2013. Failure Mode and Effect Analysis (FMEA) for Power Transformer. Tehran: Niroo Research Institute (NRI).

3. Arifani, N, I. Winarno, H. 2013. Analisis Nilai Indeks Keandalan Sistem Jaringan Disribusi Udara 20kV Pada Penyulang Pandean Lamper 1,5,8,9,10 di GI Pandean. Program Studi Diploma III Teknik Elektro Fakultas Teknik: Universitas Diponegoro.

4. Billinton. R \& Allan. R.N, 1996. Reliability Evaluation of Power System. Plenum press, New York.

5. Fatoni, A. 2016. Analisa Keandalan Sistem Distribusi 20kV PT.PLN Rayon Lumajang Dengan Metode FMEA. Jurnal : Jurusan Teknik Elektro FTI. Surabaya: Institut Teknologi Sepuluh Nopember.

6. Franklin, Onime and A. Gabriel, Adegboyega. 2014. Reliability Analysis of Power Distribution System in Nigeria: A Case Study of Ekpoma Network, Edo State. Federal University of Techno. Nigeria: Electrical and Electronics Engineering Department.

7. Nugroho, Sukmoyo, Andhito. 2012. Studi Keandalan Sistem Distribusi $20 k V$ di Bengkulu dengan Menggunakan Metode Failure Mode Effect Analysis (FMEA). Jurnal : Jurusan Teknik Elektro FTE. Surabaya: Institut Teknologi Sepuluh Nopember.

8. Prabowo,T, dkk. 2013. Analisis Keandalan Sistem Distribusi $20 k V$ Pada Penyulang Pekalongan 8 dan 12. Jurnal : Jurusan Teknik Elektro FTE. semarang: Universitas Diponegoro.

9. Tanjung, A. 2012. Analisis Sistem Distribusi $20 \mathrm{kV}$ Untuk Memperbaiki Kinerja Dan Keandalan Sistem Distribusi Menggunakan Electrical Transient Analisys Program. Jurnal : Teknik Elektro Fakultas Teknik. Pekanbaru: Universitas Lancang Kuning.

10. Widianto, F,dkk. 2013. Analisis Gangguan Hubung Singkat Tiga Fase Pada Sistem Distribusi Standar IEEE 13 Bus Dengan Menggunakan Program ETAP7.0. Jurnal : TeknikElektro. Surakarta: Universitas Surakarta.

11. Zamzami, 2013. Analisis Losses Jaringan Distribusi Primer 20 $k V$ Area Lhoksumawe. Jurnal : Politeknik Negeri Lhokseumawe. Lhokseumawe.

12. SPLN 59, Tahun 1985 


\section{Lampiran 1}

Data hasil perhitungan Penyulang Gading per-Load Point

\begin{tabular}{|c|c|c|c|c|c|c|c|c|}
\hline & $\lambda$ & $\mathrm{U}$ & $\mathrm{N}$ & SAIFI & SAIDI & CAIDI & ASAI & ASUI \\
\hline LP1 & 3.465 & 10.899 & 416 & 0.442567 & 1.392074 & 3.145455 & 0.998756 & 0.001244 \\
\hline LP2 & 3.465 & 10.899 & 201 & 0.213836 & 0.672613 & 3.145455 & 0.998756 & 0.001244 \\
\hline LP3 & 3.465 & 10.899 & 1 & 0.001064 & 0.003346 & 3.145455 & 0.998756 & 0.001244 \\
\hline LP4 & 3.465 & 10.899 & 523 & 0.5564 & 1.750131 & 3.145455 & 0.998756 & 0.001244 \\
\hline LP5 & 3.465 & 10.899 & 1 & 0.001064 & 0.003346 & 3.145455 & 0.998756 & 0.001244 \\
\hline LP6 & 3.465 & 10.899 & 1 & 0.001064 & 0.003346 & 3.145455 & 0.998756 & 0.001244 \\
\hline LP7 & 3.5152 & 11.0846 & 1 & 0.001079 & 0.003403 & 3.153334 & 0.998735 & 0.001265 \\
\hline LP8 & 3.465 & 10.899 & 1 & 0.001064 & 0.003346 & 3.145455 & 0.998756 & 0.001244 \\
\hline LP9 & 3.465 & 10.899 & 1 & 0.001064 & 0.003346 & 3.145455 & 0.998756 & 0.001244 \\
\hline LP10 & 3.465 & 10.899 & 1 & 0.001064 & 0.003346 & 3.145455 & 0.998756 & 0.001244 \\
\hline LP11 & 3.465 & 10.899 & 1 & 0.001064 & 0.003346 & 3.145455 & 0.998756 & 0.001244 \\
\hline LP12 & 3.9256 & 12.3858 & 331 & 0.398948 & 1.258735 & 3.155136 & 0.998586 & 0.001414 \\
\hline LP13 & 3.9256 & 12.3858 & 350 & 0.421848 & 1.330989 & 3.155136 & 0.998586 & 0.001414 \\
\hline LP14 & 3.9256 & 12.3858 & 665 & 0.801512 & 2.528878 & 3.155136 & 0.998586 & 0.001414 \\
\hline LP15 & 4.1428 & 13.0024 & 339 & 0.431197 & 1.353335 & 3.138554 & 0.998516 & 0.001484 \\
\hline LP16 & 4.1428 & 13.0024 & 367 & 0.466812 & 1.465115 & 3.138554 & 0.998516 & 0.001484 \\
\hline LP17 & 3.6802 & 11.5796 & 1 & 0.00113 & 0.003555 & 3.146459 & 0.998678 & 0.001322 \\
\hline LP18 & 3.465 & 10.899 & 53 & 0.056385 & 0.177356 & 3.145455 & 0.998756 & 0.001244 \\
\hline LP19 & 3.5194 & 11.0972 & 1 & 0.001081 & 0.003407 & 3.153151 & 0.998733 & 0.001267 \\
\hline LP20 & 3.465 & 10.899 & 1 & 0.001064 & 0.003346 & 3.145455 & 0.998756 & 0.001244 \\
\hline LP21 & 3.465 & 10.899 & 1 & 0.001064 & 0.003346 & 3.145455 & 0.998756 & 0.001244 \\
\hline \multirow[t]{6}{*}{ TOTAL } & & & 3257 & & & & & \\
\hline & SAIFI & & & 3.80237 & & & & \\
\hline & & SAIDI & & & 11.9697 & & & \\
\hline & & & CAIDI & & & 3.14796 & & \\
\hline & & & & ASAI & & & 0.9987 & \\
\hline & & & & & ASUI & & & 0.0013 \\
\hline
\end{tabular}




\section{Lampiran 2}

Data hasil perhitungan Penyulang Gading per-Load Point

\begin{tabular}{|c|c|c|c|c|c|c|c|c|}
\hline & $\lambda$ & $\mathrm{U}$ & $\mathrm{N}$ & SAIFI & SAIDI & CAIDI & ASAI & ASUI \\
\hline LP1 & 6.71 & 4.4697 & 1 & 0.000414 & 0.000275941 & 0.666125 & 0.99949 & 0.00051 \\
\hline LP2 & 6.71 & 4.4697 & 1 & 0.000414 & 0.000275941 & 0.666125 & 0.99949 & 0.00051 \\
\hline LP3 & 6.71 & 4.4697 & 1 & 0.000414 & 0.000275941 & 0.666125 & 0.99949 & 0.00051 \\
\hline LP4 & 6.71 & 4.4697 & 1 & 0.000414 & 0.000275941 & 0.666125 & 0.99949 & 0.00051 \\
\hline \multirow[t]{2}{*}{ LP5 } & 6.71 & 4.4697 & 562 & 0.232808 & 0.155079109 & 0.666125 & 0.99949 & 0.00051 \\
\hline & $\lambda$ & $\mathrm{U}$ & $\mathrm{N}$ & SAIFI & SAIDI & CAIDI & ASAI & ASUI \\
\hline LP6 & 6.71 & 4.4697 & 684 & 0.283346 & 0.188743968 & 0.666125 & 0.99949 & 0.00051 \\
\hline LP7 & 7.0896 & 5.6435 & 712 & 0.311631 & 0.248065934 & 0.796025 & 0.999356 & 0.000644 \\
\hline LP8 & 6.71 & 4.4697 & 1 & 0.000414 & 0.000275941 & 0.666125 & 0.99949 & 0.00051 \\
\hline LP9 & 7.0718 & 9.36286 & 221 & 0.096485 & 0.127743676 & 1.323971 & 0.998931 & 0.001069 \\
\hline LP10 & 7.0718 & 9.36286 & 221 & 0.096485 & 0.127743676 & 1.323971 & 0.998931 & 0.001069 \\
\hline LP11 & 6.71 & 10.42765 & 1 & 0.000414 & 0.000643762 & 1.554046 & 0.99881 & 0.00119 \\
\hline LP12 & 6.71 & 10.42765 & 1 & 0.000414 & 0.000643762 & 1.554046 & 0.99881 & 0.00119 \\
\hline LP13 & 6.9128 & 11.17605 & 133 & 0.05676 & 0.09176532 & 1.616718 & 0.998724 & 0.001276 \\
\hline LP14 & 6.9128 & 11.17605 & 33 & 0.014083 & 0.022768839 & 1.616718 & 0.998724 & 0.001276 \\
\hline LP15 & 6.9128 & 11.17605 & 110 & 0.046945 & 0.075896129 & 1.616718 & 0.998724 & 0.001276 \\
\hline LP16 & 6.9128 & 11.17605 & 97 & 0.041397 & 0.066926587 & 1.616718 & 0.998724 & 0.001276 \\
\hline LP17 & 6.71 & 10.42765 & 1 & 0.000414 & 0.000643762 & 1.554046 & 0.99881 & 0.00119 \\
\hline LP18 & 6.71 & 10.42765 & 1 & 0.000414 & 0.000643762 & 1.554046 & 0.99881 & 0.00119 \\
\hline LP19 & 6.71 & 10.42765 & 233 & 0.09652 & 0.149996447 & 1.554046 & 0.99881 & 0.00119 \\
\hline LP20 & 6.71 & 10.42765 & 313 & 0.12966 & 0.201497373 & 1.554046 & 0.99881 & 0.00119 \\
\hline LP21 & 6.71 & 10.42765 & 1 & 0.000414 & 0.000643762 & 1.554046 & 0.99881 & 0.00119 \\
\hline LP22 & 6.71 & 10.42765 & 346 & 0.14333 & 0.222741505 & 1.554046 & 0.99881 & 0.00119 \\
\hline LP23 & 6.71 & 8.20746 & 155 & 0.064209 & 0.078537863 & 1.223168 & 0.999063 & 0.000937 \\
\hline LP24 & 6.71 & 8.20746 & 1 & 0.000414 & 0.000506696 & 1.223168 & 0.999063 & 0.000937 \\
\hline LP25 & 6.71 & 8.20746 & 851 & 0.352526 & 0.431198201 & 1.223168 & 0.999063 & 0.000937 \\
\hline LP26 & 6.71 & 8.20746 & 468 & 0.193868 & 0.237133676 & 1.223168 & 0.999063 & 0.000937 \\
\hline LP27 & 6.71 & 8.20746 & 1 & 0.000414 & 0.000506696 & 1.223168 & 0.999063 & 0.000937 \\
\hline LP28 & 6.71 & 8.20746 & 1 & 0.000414 & 0.000506696 & 1.223168 & 0.999063 & 0.000937 \\
\hline LP29 & 6.71 & 8.20746 & 1 & 0.000414 & 0.000506696 & 1.223168 & 0.999063 & 0.000937 \\
\hline LP30 & 6.71 & 8.20746 & 221 & 0.091549 & 0.111979791 & 1.223168 & 0.999063 & 0.000937 \\
\hline LP31 & 6.71 & 8.20746 & 1 & 0.000414 & 0.000506696 & 1.223168 & 0.999063 & 0.000937 \\
\hline LP32 & 6.71 & 9.05508 & 240 & 0.09942 & 0.134165897 & 1.34949 & 0.998966 & 0.001034 \\
\hline LP33 & 7.0566 & 10.16488 & 1 & 0.000436 & 0.000627539 & 1.440478 & 0.99884 & 0.00116 \\
\hline LP34 & 7.0566 & 10.16488 & 669 & 0.291447 & 0.419823726 & 1.440478 & 0.99884 & 0.00116 \\
\hline LP35 & 7.509 & 11.59208 & 83 & 0.038477 & 0.059398854 & 1.543758 & 0.998677 & 0.001323 \\
\hline LP36 & 7.509 & 11.59208 & 201 & 0.093179 & 0.143845418 & 1.543758 & 0.998677 & 0.001323 \\
\hline LP37 & 7.509 & 11.59208 & 38 & 0.017616 & 0.027194656 & 1.543758 & 0.998677 & 0.001323 \\
\hline LP38 & 7.509 & 11.59208 & 5 & 0.002318 & 0.003578244 & 1.543758 & 0.998677 & 0.001323 \\
\hline LP39 & 6.71 & 9.05508 & 418 & 0.173156 & 0.233672271 & 1.34949 & 0.998966 & 0.001034 \\
\hline
\end{tabular}




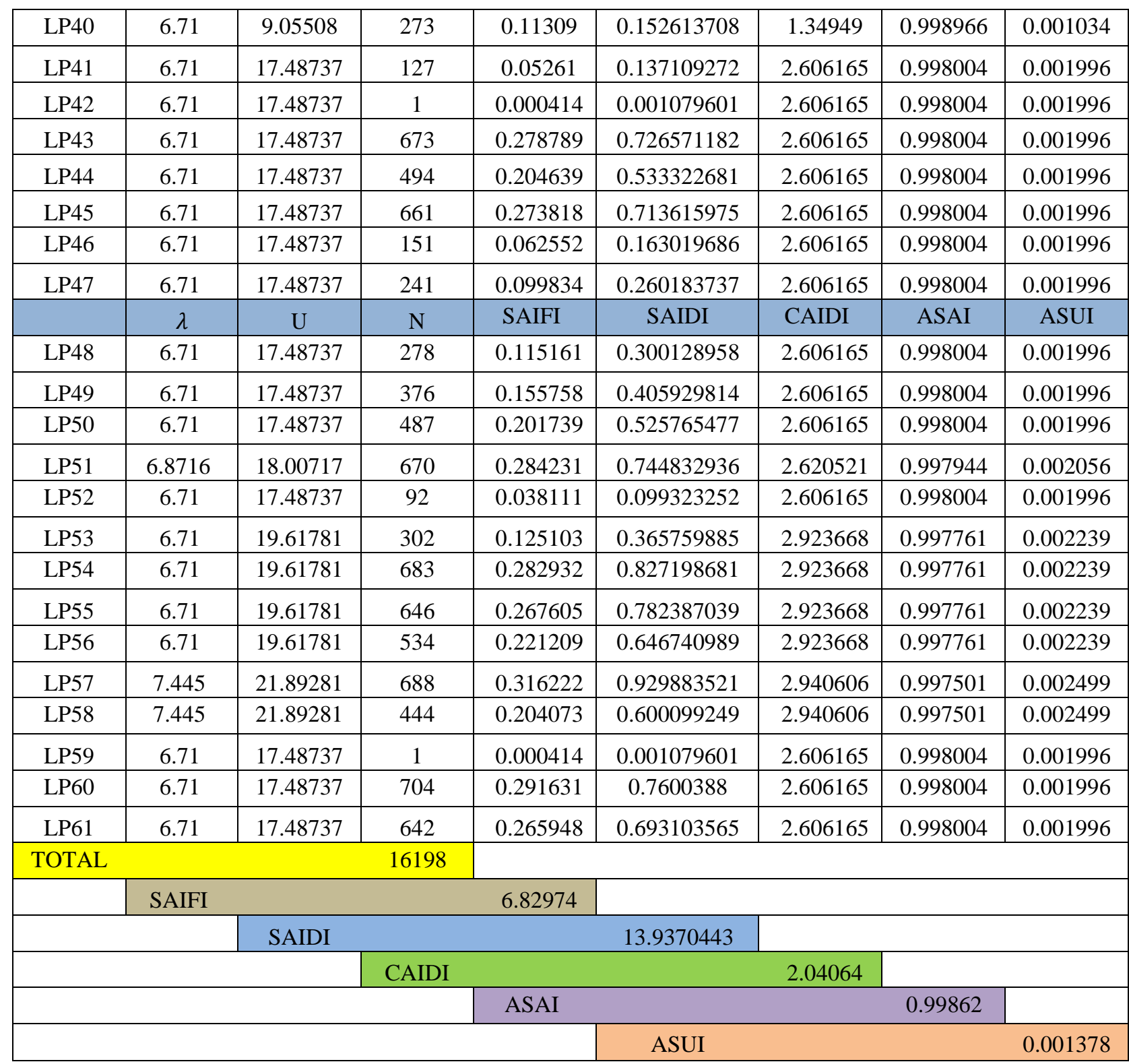

